PROBLEMS

OF EDUCATION IN THE $21^{\text {st }}$ CENTURY Vol. 78 , No. 1, 2020

24

\title{
IMPLEMENTATION OF MOBILE LEARNING USING A SOCIAL NETWORK PLATFORM: FACEBOOK
}

\author{
John, G. Chaka, Irene Govender \\ University of KwaZulu-Natal, South Africa \\ E-mail: chakajohn@yahoo.com,govenderi4@ukzn.ac.za
}

\begin{abstract}
This research set out to determine the use of a social networking platform, Facebook, as a medium for learning and teaching. Using a combination of the unified theory of acceptance and use of technology (UTAUT) model, Information Systems (IS) success model and the educational use of Facebook theory, a conceptual framework was developed for implementation of mobile learning and teaching. Structural equation modelling (SEM) was used to determine a model for the implementation of mobile learning and teaching. A sample of 330 respondents was used in this research. The data were analysed using structural equation modelling. The aim was to determine to what extent mobile learning is acceptable to colleges of education in Nigeria. Lecturers from a federal college of education in Nigeria were used to test the implementation of mobile learning using Facebook as a medium of communication. Four courses were selected as part of the intervention programme. The research revealed that m-learning significantly improves the teaching and learning conditions in colleges of education, specifically by reducing the inadequacies of physical facilities, and by improving the reading culture and performance of students. The results further indicate that most of the stakeholders are satisfied with the benefits of m-learning and wish to continue using the Facebook and their mobile phones.
\end{abstract}

Keywords: educational system, quantitative approach, mobile learning, Facebook, SEM.

\section{Introduction}

The United Nations Education, and Scientific Corporation - UNESCO (as cited in Otoo (2015)) has stated that Nigeria leads the world in terms of the number of people that have difficulty in accessing education. The inadequacy of the teaching and learning environments in most educational institutions especially at the tertiary level may have aggravated the situation. Most higher education institutions in the country lack the needed facilities, for example classrooms, books and other relevant educational materials (Asiyai, 2013; Ilogho, 2015; Jaja, 2013; Okojie, 2013). In addition, most Nigerian higher education institutions still depend on time-honoured teaching and learning methods, which are largely constrained by using the physical infrastructure such as classrooms, and libraries, which are not always suitable for teaching and learning. This makes it difficult for the Nigerian education institutions to cater to the increasing number of students who seek entrance to tertiary education, which gave impetus for this research.

Based on the positive results obtained from preliminary studies (Chaka \& Govender, 2017a; Chaka \& Govender, 2017b), which revealed that both lecturers and students were accepting the use of mobile devices to teach and learn, it became necessary to test the implementation of mobile learning to see how the acceptance and success measures work together. This research ascertains the viability and success of mobile learning in improving the teaching and learning conditions in Colleges of Education. Specifically, the Facebook application was used as the 
mobile learning medium. Most stakeholders in Colleges of Education have been using this application as ascertained from a preliminary study (Chaka, 2018). This research reports on part of a larger research study (Chaka, 2018).

\section{Literature Review}

\section{Related Literature}

Serbessa (2006, p. 129) described the time-honoured teaching method as the "chalk and talk" lecture approach where the students are passive recipients of knowledge. The teacher is at the centre of the teaching process using a rigid curriculum structure to teach all students in the same manner (Ahmed, 2013; Bishara, 2015). The problem with this approach is that access to education, depends on availability of physical infrastructure such as classrooms while learning depends on the teachers' competence. Thus, Clark and Ausukuya (2013) reported that the insufficient number of teachers in most higher education institutions has resulted in teacher-student ratios as high as 1:356 in some cases, as against the recommended ratio of $1: 25$. This has affected not just the quality of training and performance of existing students, but also the enrolment of new students thereby increasing the access gap to education in the country. Klopfer, Osterweil, Groff and Haas (2009) argued that social networks have all the characteristics and potential of achieving good learning, as users are now creating, learning, and communicating in new ways. Thus, since time, lack of skills and lack of money constitute the major barriers to the use of conventional Virtual Learning Environment (VLEs) (Walker et al., 2014), the application of social networking sites in education seems to address these challenges. Corroborating this position, Selwyn (2012) stated that, perhaps the driving force behind the educational use of social networking sites is the nature of students that are enrolling in the institutions. Selwyn $(2012$, p. 2) further described the incoming students as those "who know nothing other than a life with the internet."

In the light of the above, Alsereihy and Al Youbi (2014) have asserted that with the exponential increase in the popularity of social networking media, higher education institutions are beginning to embrace their applications for various educational purposes. They maintain that a number of Universities in the Western world today have included social networking sites as part of their platform to facilitate communication, research and collaboration among stakeholders. Thus, with the social interactive, communication and collaborative features of Social Networking Sites (SNS) which are lacking in most conventional learning management systems (LMSs), social networking sites are believed to be well-positioned to support teaching and learning (Buzzetto-More, 2012; Mazman \& Usluel, 2010). They further argued that social networking sites, specifically Facebook, have the capacity to facilitate online discussions and collaboration among students, and between students and teachers, in addition to providing opportunities for the sharing of ideas, educational content as well as enhancement of communication among stakeholders. This is very important in light of the fact that the current generation of students are digital natives. This compels learning to be socially and digitally driven by ubiquitous technologies (Buzzetto-More, 2012). They maintain that since social networking sites are being used extensively by many people, their application to education is long overdue in view of the numerous advantages including learner-centred, collaboration, and active participation among others. They further stated that most people have a preference for communicating online instead of the traditional face-to-face approach. Yapici and Havedanli (2014), maintain that since most teachers and students are users of social networks, with Facebook having the largest population (e.g. 34\% of Facebook users in Turkey are higher education students), the application of social networks in facilitating teaching and learning will certainly be rewarding. In this sense, Ahn (2011) argued that the youth of today 
PROBLEMS

OF EDUCATION IN THE $21^{\text {st }}$ CENTURY Vol. 78 , No. 1,2020

26

communicate and learn more from outside the school premises. Thus, engaging in interactions using social networking sites is viewed as a form of literacy practice which contributes to learning. According to Adewole and Fakorede (2013), appropriation is a skill which enables the communication of ideas by remixing content from different sources. They posit that social networking sites provide the tools to enable students to gather, synthesize and remix content, thereby acquiring skills and knowledge. Similarly, Clark and Ausukuya (2013), stated that networking is the capacity to search, integrate, and disseminate information, which social networking sites provide.

In view of this, the next section examines the extent to which social networking sites have been useful in teaching and learning.

\section{Application of Social Networking in Teaching and Learning}

In what appears like the first stage of studies to establishing a link between the use of SNS and educational performance, Karpinski and Duberstein (2009) conducted a survey among students of Ohio Dominican University to ascertain if there was a link between the use of Facebook and educational performance. Although part of the findings of Karpinski and Duberstein (2009) indicated that Facebook users had lower performance than non-Facebook users, their study did not suggest that Facebook use led to lower performance, as there could be other factors such as personality traits. Building on this, Pasek, More, and Hargittai (2009) examined the association between social networking use and learning outcomes among undergraduate students, and they found that Facebook usage had no link with GPA. They therefore suggested further research to explore the association between Facebook and academic performance of students.

Laying a theoretical foundation on the application of SNS in education, Mazman and Usluel (2009) proposed a model for the educational use of social networking sites. Their model was conceived from previous innovation and technology acceptance models. Following this initial conception, Mazman and Usluel (2010) came up with a structural model to explain how users can use social networking sites specifically Facebook for educational purposes. The researchers tested out their model and found that user-purposes and adoption processes accounted for $50 \%$ of the variance in educational use of Facebook while Facebook adoption processes explained $86 \%$ of user purposes. In other words, while Facebook adoption processes alone accounted for $45 \%$ of variance in educational use of Facebook, the joined effects of Facebook adoption processes and user purposes accounted for $50 \%$ of the variance in education use of Facebook.

Additionally, in a bid to understand the efficacy of social networking sites as instructional tools, Buzzetto-More (2012) examined the perceptions of management students who have already completed courses. As part of his methodology, the researcher integrated Facebook use into some courses that were taken by management students for at least one academic semester. Facebook was used to create course groups for the courses involved and all students who had registered for the various courses were required to join. The findings from their study revealed that $33 \%$ of the participants indicated that they stay online for 3-8 hours per week engaged in social networking sites, and that $47 \%$ of them agreed that Facebook develops interpersonal relationships. In addition, Buzzetto-More (2012) found that social networking sites especially Facebook can strengthen relationships within learning communities as 47 per cent of the students agreed that Facebook can enhance their learning process. The report further reveals that $50 \%$ of the students see Facebook as a good tool to engage in learning. To further verify the use of SNS, Shembilu (2013) examined the benefits of social networking in education in Tanzania. The study found that the majority of the students $(96 \%)$ use social networking sites to socialize with peers while a reasonable number $(63 \%)$ use social networking sites 
for sharing academic-related information. Shembilu (2013) also found out that Facebook was the most preferred social networking site while blogs ranked second. The study further revealed that $65 \%$ of the respondents feel that social networking sites can serve both social and academic needs of students. Regarding measures that needed to be put in place to facilitate the educational use of SNS, sensitization of students and educators was ranked first (87\%) followed by provision of Internet access (68\%), and distribution of Internet and ICT facilities nationwide (42\%). Forcing government to provide free Internet centres was ranked last (12\%).

Shembilu (2013) concluded that although participants see the educational use of social networking sites as promising, and that there was some evidence of the educational use of SNS in Tanzania, not much sensitization had been done to widen the scope of usage. In addition, challenges of ICT infrastructure and cost of Internet bandwidth served as obstacles. Similarly, in order to assess the viability of SNS sites in facilitating teaching and learning, Dunn (2013) focused on the application of mobile and portable devices. Dunn (2013) found that the majority of students (92\%) use one form of social networking medium or the other, with Facebook (86\%) being the most popularly used. The study further indicated that $87 \%$ of subscribers use SNS for personal use, 33\% for networking with other professionals while $24 \%$ use it for research-related activities. Regarding the belief of students in the helpfulness of social networking sites for learning, his study reveals that $75 \%$ of the students found social networking sites very helpful in learning. In a more recent study, Gülbahar (2014) found that students have positive perceptions on the use of social media in education but are, however not aware of the various facilitating tools that these technologies offer. A very recent study by Gorghiu, Iordache, Pribeanu, and Lamanauskas (2018) revealed that if students use Facebook for learning purposes, it is mainly for sharing learning material and collaboration.

Alsereihy and Al Youbi (2014) argued that the positive reports that are emanating from the western world on the usage and application of social networking sites in education cannot not be generalized to other countries. In the light of this, they examined the usage of social networking sites by higher education institutions in Saudi Arabia. Alsereihy and Al Youbi (2014) found among other things that the use of social networking applications was prevalent in major Universities in Saudi Arabia. They further found that Facebook was leading in terms of usage and awareness, but that the use of social networking sites as collaborating and educational tools was underutilized amidst privacy and security concerns.

Despite the promises of social networking sites and mobile learning in facilitating teaching and learning, no known study has integrated the use of mobile learning with social networking sites in Nigeria, especially in the context of Colleges of Education. Some studies (such as Adedoja et al., 2013; Osang \& Ngole, 2014; Shaibu \& Mike, 2014) have investigated mobile learning in Universities but not with social networking sites as the learning platform. The situation in other higher education institutions remains unclear in view of different affordances, which are key determinants of any research output (Traxler, 2007; Thomas et al., 2013). Colleges of Education are vital, based on their role as teacher training institutions, but are most affected in terms of the challenges that are confronting teaching and learning in Nigerian higher education institutions (Ogunyinka et al., 2015; Tella, 2011). Therefore, exploring the use of mobile learning in improving the teaching and learning conditions in higher education institutions, specifically Colleges of Education has become imperative. In view of the affordability and commonality of SNS, their use as the learning platform is considered.

Hence, this research was guided by the following research questions:

1. To what extent do the acceptance factors (performance expectancy, effort expectancy, social influence, mobile learning conditions, anxiety \& personal innovativeness) jointly with user satisfaction influence the behavioural intention of participants to use Facebook as a medium to teach? 
John, G. CHAKA, Irene GOVENDER. Implementation of mobile learning using a social network platform: Facebook

PROBLEMS

OF EDUCATION

IN THE $21^{\text {st }}$ CENTURY

Vol. 78, No. 1,2020

2. To what extent do mobile learning conditions, behavioural intention, and user satisfaction influence the actual use of mobile learning?

3. How does the actual use of mobile learning and user satisfaction result in an improved educational system?

\section{Conceptual Framework}

In order to guide this research towards achieving its aim, an appropriate conceptual framework is required. Most of the studies reviewed in the literature made use of the unified theory of acceptance and use of technology (UTAUT) or variations of the theory to understand the acceptance or intention and usage of mobile learning in higher education. However, one limitation of UTAUT in relation to this study is that UTAUT only measures the likelihood of users to accept a technology and the users' intended usage behaviour of the technology (Venkatesh et al., 2003). In other words, UTAUT is mainly suitable for use prior to the application or implementation of a technology. By implication, UTAUT alone is unable to address the objectives of this study. Three models - the UTAUT model, the IS success model, and the educational use of Facebook model are considered critical in explaining the acceptance and use of mobile learning, as well as educational use of social networking sites. While the IS success model is considered suitable in view of its capacity to measure the success of the application of information systems in organisations, the educational use of Facebook model brings into the study constructs that are peculiar to the use of Facebook.

\section{Figure1}

Conceptual framework of the research

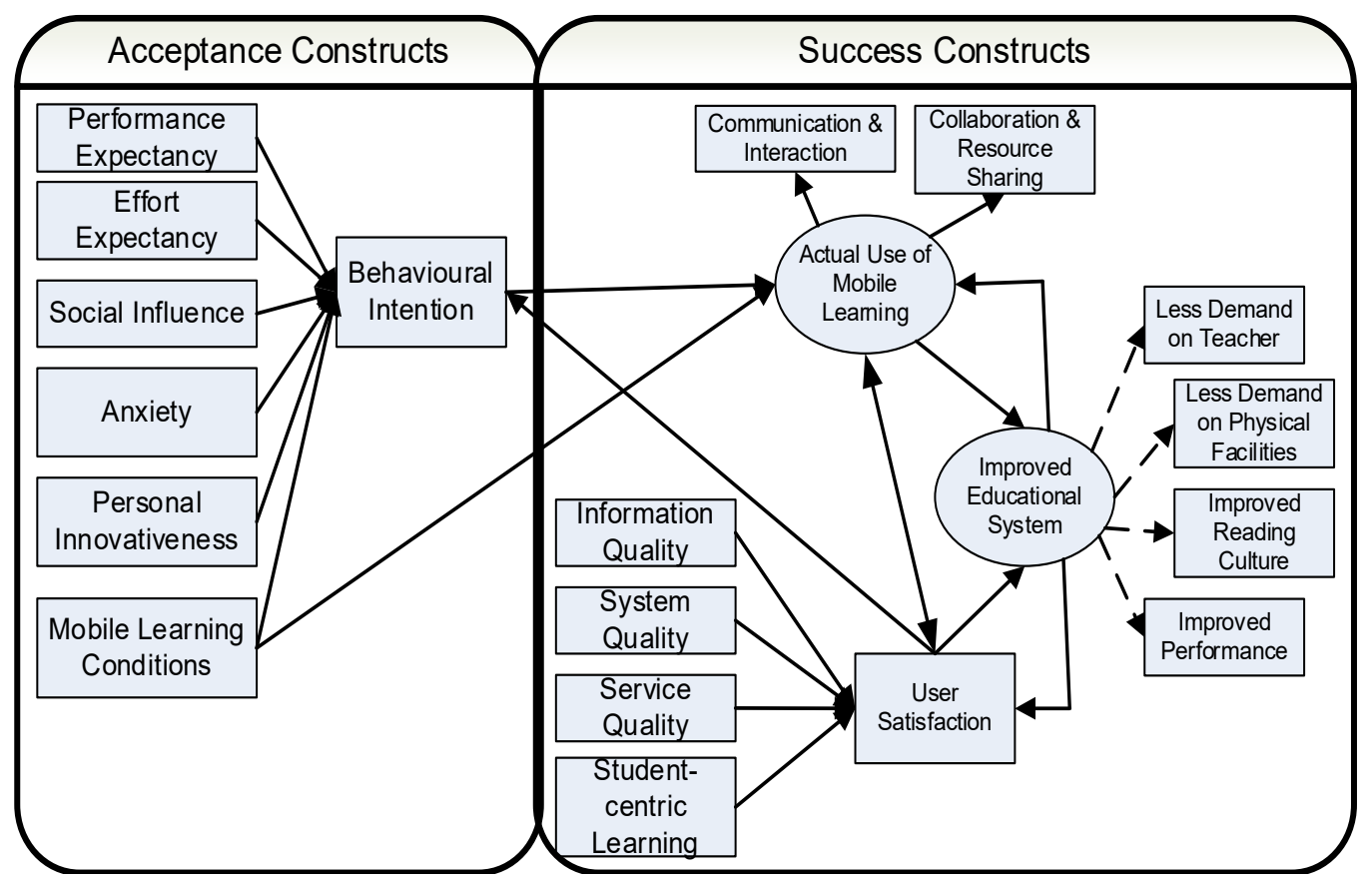




\title{
Research Methodology
}

\author{
Research Approach and Design
}

The quantitative approach followed the survey research strategy. This was to enable the possibility of generalizing the findings of the research to the entire population. The survey design was considered more feasible in this research in view of its advantages, most especially cost saving (Kumar, 2011). In addition, it was easier and advantageous to measure the attributes of a population from a smaller group (Creswell, 2014). This was imperative since Nigeria is one of the largest countries in Africa (landmass of $923,768 \mathrm{~km}^{2}$ ).

\section{Research Site}

The research was conducted in a College of Education in Nigeria, specifically in the North-central geopolitical zone of the country. This zone was selected in view of its cosmopolitan nature. Apart from being the zone where the nation's capital (Abuja) is located, the zone is in the centre of the country and draws from the diverse cultures of almost all the ethnic groups in Nigeria.

\section{Intervention - Preparation of Lecturers for Implementation}

As part of the implementation process, the following guidelines were specifically provided to lecturers to follow:

1. Create a group in Facebook and name the group after the course that you are teaching (e.g. call the group DBE 221) if DBE 221 is the course to be taught;

2. Enrol your students as members of the group. Also add me (researcher) as a member of the group;

3. All activities should be performed using mobile devices (phones and possibly tablets) only.

4. Engage your students in various teaching and learning activities such as:

a. Discussion forum: Post a question or topic that is relevant to the course and allow students to discuss it freely while the teacher facilitates.

b. Sharing and collaboration: Encourage students to do more research into the topic and share relevant links with colleagues in the group. The teacher can also share relevant links, documents, files, videos, etc. in the groups.

c. Assessment: Teachers can post assignment as a document or file to the group and advise students to submit the same through a private message to them.

d. Motivation: Teachers should encourage participation of students by awarding marks to very active participants and to quality contributors in the group.

e. Ubiquitous: since mobile devices are being used, participants should be engaged with the exercises at anytime and anywhere.

\section{Population and Sample}

Lecturers from a College of Education were used to test the use of mobile learning by using the technology to supplement the teaching of four selected courses (CS 412, DBE 221, GUC 205, SSE 313). One college was used to pilot the implementation of the use of social network site for effective management and monitoring of the exercise. Since the researcher was a member of staff, it was easy to gain access to the system as well as obtain the cooperation of the staff and students. Kumar (2011) posits that bias can be introduced by a researcher if it becomes difficult to penetrate the population. 
John, G. CHAKA, Irene GOVENDER. Implementation of mobile learning using a social network platform: Facebook

PROBLEMS

OF EDUCATION

IN THE $21^{\text {st }}$ CENTURY

Vol. 78 , No. 1,2020

30

Four lecturers from four of the five schools in the college were part of the intervention. The schools included were School of Arts and Social Sciences, School of Education, School of Sciences, and School of Vocational and Technical Education. Based on Creswell's (2014, p.93) list of ethical issues and possible ways of addressing them, this study adhered to the following ethical procedure: Permission was sought and granted from the National Commission for Colleges of Education (NCCE) - to undertake the study in Colleges of Education. A written approval was then granted by the College of Education. For all individuals that were involved in the study, their consent was obtained through a letter that was attached to the data collection instrument.

The researcher used his experience as an insider to select lecturers that were more knowledgeable in the use of computer and social networking applications. A social networking site (Facebook) was used as the teaching and learning platform. This is in view of the availability of the application, its user friendliness and compatibility with most mobile devices, and the fact that most members of the colleges were already using it. Based on Krejcie and Morgan's (1970) table and Kumar's (2011) suggestion, a study sample of 330 was considered adequate for the implementation of the research. A sample of 330 students was used in this study. The data were analysed using structural equation modelling.

\section{Data Collection Instruments}

The questionnaire used consisted of two sections - Section ' 1 ' obtained demographic information while Section '2' elicited information regarding the use of mobile learning in line with the constructs contained in the conceptual framework of the research. The items in the questionnaire were measured on a 5-point Likert scale ranging from $1=$ strongly disagree to 5 $=$ strongly agree. Different components of the questionnaire items were adapted from various sources. The first set of 26 items which measured the acceptance of mobile learning using a social networking site (Facebook) were adopted from Venkatesh et al., (2003) and Abu-AlAish and Love (2013). The second set of 48 items which measured the actual use and success of mobile learning were adopted from a number of sources (Alharbi \& Drew, 2014;Delone \& McLean, 2003; Lin et al., 2016). All the scales used in the research had good internal consistency reliability ratings, with most of them above .9 .

\section{Data Analysis}

Categorical demographic variables were analysed or explored from different perspectives using cross-tabulations, while continuous variables were analysed using descriptive statistics including mean and standard deviation. Structural equation modelling (SEM) was used to test the fitness of the model to the data and to explore various relationships in the conceptual model in order to provide answers to the research questions. SEM was considered suitable to use in the implementation stage to enable the researcher test the conceptual framework which was a new conception (Kumar, 2011; Pallant, 2011).

A total number of 330 questionnaires were distributed to the respondents using the physical (face-to-face) method out of which 324 were retrieved. Three of the questionnaires were later discarded for inconsistency resulting in 321 useable questionnaires and a final response rate of $97 \%$.

\section{Research Results}

\section{Descriptive Results}

The descriptive results emerged from the analysis of demographic information. Table 1 shows a cross-tabulation of stakeholders grouped by gender. 
Table 1

\begin{tabular}{|c|c|c|c|c|}
\hline \multirow{2}{*}{ Male } & & \multicolumn{2}{|c|}{ Gender } & \multirow{2}{*}{ Total } \\
\hline & & Female & & \\
\hline \multirow{2}{*}{ Stakeholders' group } & Student & 184 & 133 & 317 \\
\hline & Lecturer & 4 & 0 & 4 \\
\hline Total & & 188 & 133 & 321 \\
\hline
\end{tabular}

From Table 1, it is apparent that the target population consisted of more males than females, in particular there were only male lecturers who participated in this research.

Table 2 gives some indication of the characteristics of the participants.

Table 2

Analysis of demographic information for continuous variables

\begin{tabular}{|c|c|c|c|c|c|c|c|c|c|}
\hline & $N$ & Min & Max & Mean & $S D$ & \multicolumn{2}{|c|}{ Skewness } & \multicolumn{2}{|c|}{ Kurtosis } \\
\hline Age & 321 & 19 & 52 & 26.98 & 5.156 & 1.561 & .136 & 3.575 & .271 \\
\hline $\begin{array}{l}\text { Use of mobile } \\
\text { device } \\
\text { experience }\end{array}$ & 321 & 1 & 12 & 4.12 & 2.355 & .797 & .136 & .208 & .271 \\
\hline Valid $N$ (listwise) & 321 & & & & & & & & \\
\hline
\end{tabular}

Table 2 shows that the minimum age of the respondents is 19 years while the maximum age is 52 years. The average age was 26.98. From the Table, it is gathered that the age of the respondents is positively skewed; meaning that majority of the respondents lie below the average age of 26.98. Table 2 further reveals that the respondents have used mobile devices for a minimum of one year and a maximum of 12 years.

\section{Quantitative Data Analysis Procedure Using SEM}

SEM using IBM Amos version 23 was used to analyse the data by exploring various relationships that exist in the proposed or conceptual framework. The primary goal of SEM is to determine and validate a proposed causal process or a model. In other words, the model used in the research was specified as the conceptual framework, subject to confirmation. We have a covariance matrix to serve as our dataset, which is based on the sample of collected measurements. The empirical question of SEM is therefore whether the proposed model produces a population covariance matrix that is consistent with the sample covariance matrix. Hence the model specified/proposed needs to be validated/ tested.

Therefore, using SEM is considered suitable to test the conceptual model, which is a new formulation. The interplay between different variables provides the answers to the research questions. In order to apply SEM, the data must satisfy a number of assumptions. Thus, as part of the process of analysis, the data in this study was first cleaned up and tested for the nonviolation of the assumptions of SEM. 
John, G. CHAKA, Irene GOVENDER. Implementation of mobile learning using a social network platform: Facebook

PROBLEMS

OF EDUCATION

IN THE $21^{\text {st }}$ CENTURY

Vol. 78, No. 1,2020

32

\section{Testing for non-violation of assumptions}

To conduct SEM, the data must meet two criteria, completeness and normality. There was no need to adopt any ad hoc measure since no missing data was present.

Normality was checked by looking at skewness and kurtosis for all variables in the model. The normality of the data on the dependent and/or mediating variables in the model (behavioural intention, and user satisfaction) were found to appear normal (skewness $<=3$ and Kurtosis $<=10$ ) (Pallant, 2011). This was done by assessing the effect of 5\% trimmed mean on actual values. Skewness, and kurtosis of each measured (observable) dependable variable as shown in Table 3 . The 5\% trimmed mean refers to the computed mean excluding $5 \%$ of the upper (largest) and lower (smallest) values of the distribution.

\section{Table 3}

Trimmed mean, skewness and kurtosis statistics for dependent variables

\begin{tabular}{|c|c|c|c|c|}
\hline \multicolumn{5}{|c|}{ Descriptive } \\
\hline & & & Statistic & Std. Error \\
\hline \multirow{13}{*}{$\mathrm{BI}$} & Mean & & 7.07 & .101 \\
\hline & \multirow{2}{*}{ 95\% Confidence Interval for Mean } & Lower Bound & 6.88 & \\
\hline & & Upper Bound & 7.27 & \\
\hline & $5 \%$ Trimmed Mean & & 7.15 & \\
\hline & Median & & 7.00 & \\
\hline & Variance & & 3.307 & \\
\hline & Std. Deviation & & 1.818 & \\
\hline & Minimum & & 2 & \\
\hline & Maximum & & 10 & \\
\hline & Range & & 8 & \\
\hline & Interquartile Range & & 2 & \\
\hline & Skewness & & -.654 & .136 \\
\hline & Kurtosis & & .157 & .271 \\
\hline \multirow{13}{*}{ US } & Mean & & 10.35 & .144 \\
\hline & \multirow{2}{*}{ 95\% Confidence Interval for Mean } & Lower Bound & 10.06 & \\
\hline & & Upper Bound & 10.63 & \\
\hline & $5 \%$ Trimmed Mean & & 10.42 & \\
\hline & Median & & 11.00 & \\
\hline & Variance & & 6.652 & \\
\hline & Std. Deviation & & 2.579 & \\
\hline & Minimum & & 3 & \\
\hline & Maximum & & 15 & \\
\hline & Range & & 12 & \\
\hline & Interquartile Range & & 3 & \\
\hline & Skewness & & -.509 & .136 \\
\hline & Kurtosis & & -.042 & .271 \\
\hline
\end{tabular}


Sample size is also an important factor in SEM. Although there may be no consensus regarding the sample size appropriate for SEM analysis (Sivo et al., as cited in (Hoe, 2008)), it is suggested that large samples of say 200 and above may result in the needed level of statistical power with any given model (Schreiber, Nora, Stage, Barlow, \& King, 2006). Hence, the sample size of 321 utilized in this study is considered appropriate for applying SEM.

\section{Exploratory Factor Analysis and Validation of Measurement Model}

As part of the refinement process of the measurement model, exploratory factor analysis is used to assess the factor loadings of all items that estimate each construct. Due to the complexity of the conceptual model of the study, each of the 4 sub-models were taken individually and tested for 'uni-dimentionality' and cross-loading. Reliability and validity were calculated and, based on these results, adjustments were made. These adjustments included adding in covariance indicators to error variances and removing any measured items with low loadings or indications of cross-loading.

After the sub-models were treated individually and the 'best' sub-models achieved, they were taken together in pairs and then three at a time and the same process was carried out. Information regarding each construct in the measurement model with the number of factors entered and retained is presented in Table 4. 
John, G. CHAKA, Irene GOVENDER. Implementation of mobile learning using a social network platform: Facebook

PROBLEMS

OF EDUCATION

IN THE $21^{\text {st }}$ CENTURY

Vol. 78 , No. 1,2020

$\frac{1,2020}{34}$

Table 4

Information on various constructs in the measurement model

\begin{tabular}{|c|c|c|}
\hline Construct & Initial number of items & Number of items retained \\
\hline \multicolumn{3}{|l|}{ Sub-model A } \\
\hline Performance expectancy & 4 & 2 \\
\hline Effort expectancy & 4 & 3 \\
\hline Social Influence & 4 & 2 \\
\hline Anxiety & 3 & 3 \\
\hline Personal innovativeness & 3 & 2 \\
\hline Mobile learning conditions & 4 & 3 \\
\hline Behavioural intention & 4 & 2 \\
\hline \multicolumn{3}{|l|}{ Sub-model B } \\
\hline Communication \& interaction & 5 & 3 \\
\hline Collaboration \& resource sharing & 4 & 2 \\
\hline \multicolumn{3}{|l|}{ Sub-model C } \\
\hline Information quality & 7 & 5 \\
\hline System quality & 5 & 4 \\
\hline Service quality & 6 & 5 \\
\hline Student-centric learning & 3 & 2 \\
\hline User satisfaction & 3 & 3 \\
\hline \multicolumn{3}{|l|}{ Sub-model D } \\
\hline Less demand on teacher & 3 & 2 \\
\hline Less demand on physical facilities & 3 & 3 \\
\hline Improved reading culture & 5 & 3 \\
\hline Improved performance & 4 & 2 \\
\hline
\end{tabular}

Fitness of the Model

To assess the fitness of the model, fit indices were used. Since it is not necessary or realistic to report all the fit indices produced by SEM application, Hooper et al., (2008) have recommended that, in addition to Chi-square value, its degree of freedom and the $p$-value, a variety of the indices which tests different aspects of the model fit should also be reported. In accordance with this discussion, this research reports at least one fit index from each test group. The chi-square value (CMIN or $\left.\chi^{2}\right)$, degree of freedom $(d f)$, chi-square value over degree of freedom (CMIN or $\chi^{2} / d f$ ), RMSEA, GFI, IFI, TLI, and CFI were reported for each model test.

For the integrated model proposed in this research, it was found that the best fit indices that could be obtained without dropping any of the constructs were not entirely within the prescribed values as can be seen in Table 5 . 
Table 5

Overall fit indices of the proposed measurement model

\begin{tabular}{cc}
\hline Fit Index & Observed Value \\
\hline CMIN & 1543.415 \\
\hline $\mathrm{df}$ & 1040 \\
\hline CMIN/Df & 1.484 \\
\hline GFI & .847 \\
\hline IFI & .909 \\
\hline TLI & .890 \\
\hline CFI & .906 \\
\hline RMSEA & .039 \\
\hline
\end{tabular}

As can be seen from Table 5, with the exception of GFI and TLI which are adequate or marginally acceptable, all the indices indicate a good fit (Barrett, 2007; Hoe, 2008). The model was then tested for reliability and validity, which are presented in Table 6. 
John, G. CHAKA, Irene GOVENDER. Implementation of mobile learning using a social network platform: Facebook

PROBLEMS

OF EDUCATION IN THE $21^{\text {st }}$ CENTURY Vol. 78 , No. 1,2020 36

Table 6

Reliability and validity measures of the proposed measurement model

\begin{tabular}{|c|c|c|c|c|c|c|c|}
\hline Construct & Items & Loadings & $\begin{array}{c}\text { Cronbach's } \\
\text { alpha }\end{array}$ & CR & AVE & MSV & MIC \\
\hline \multirow[t]{2}{*}{ Performance expectancy } & PE2 & 0.854 & 0.747 & 0.765 & 0.625 & 0.228 & 0.410 \\
\hline & PE3 & 0.698 & & & & & \\
\hline \multirow[t]{3}{*}{ Effort expectancy } & EE1 & 0.700 & 0.695 & 0.687 & 0.423 & 0.394 & 0.419 \\
\hline & EE2 & 0.612 & & & & & \\
\hline & EE3 & 0.653 & & & & & \\
\hline \multirow[t]{2}{*}{ Social Influence } & $\mathrm{SI} 2$ & 0.656 & 0.684 & 0.690 & 0.530 & 0.228 & 0.381 \\
\hline & SI3 & 0.792 & & & & & \\
\hline \multirow[t]{3}{*}{ Mobile learning conditions } & MLC1 & 0.690 & 0.694 & 0.688 & 0.425 & 0.394 & 0.382 \\
\hline & MLC2 & 0.670 & & & & & \\
\hline & MLC3 & 0.613 & & & & & \\
\hline \multirow[t]{3}{*}{ Anxiety } & AX1 & 0.589 & 0.718 & 0.723 & 0.469 & 0.032 & 0.458 \\
\hline & $\mathrm{AX} 2$ & 0.788 & & & & & \\
\hline & $\mathrm{AX} 3$ & 0.661 & & & & & \\
\hline \multirow[t]{2}{*}{ Personal innovativeness } & $\mathrm{Pl} 1$ & 0.819 & 0.757 & 0.761 & 0.615 & 0.119 & 0.484 \\
\hline & $\mathrm{PI} 2$ & 0.746 & & & & & \\
\hline \multirow[t]{2}{*}{ Behavioural intention } & $\mathrm{Bl} 1$ & 0.798 & 0.657 & 0.661 & 0.497 & 0.262 & 0.369 \\
\hline & $\mathrm{Bl} 2$ & 0.616 & & & & & \\
\hline \multirow[t]{5}{*}{ Information quality } & IQ1 & 0.538 & 0.803 & 0.795 & 0.441 & 0.408 & 0.387 \\
\hline & IQ2 & 0.681 & & & & & \\
\hline & IQ3 & 0.678 & & & & & \\
\hline & IQ4 & 0.770 & & & & & \\
\hline & IQ5 & 0.639 & & & & & \\
\hline \multirow[t]{4}{*}{ System quality } & SQ1 & 0.452 & 0.648 & 0.664 & 0.402 & 0.209 & 0.339 \\
\hline & SQ2 & 0.642 & & & & & \\
\hline & SQ3 & 0.573 & & & & & \\
\hline & SQ5 & 0.682 & & & & & \\
\hline \multirow[t]{5}{*}{ Service quality } & SVQ2 & 0.647 & 0.745 & 0.765 & 0.395 & 0.375 & 0.357 \\
\hline & SVQ3 & 0.640 & & & & & \\
\hline & SVQ4 & 0.600 & & & & & \\
\hline & SVQ5 & 0.637 & & & & & \\
\hline & SVQ6 & 0.616 & & & & & \\
\hline \multirow[t]{3}{*}{ User satisfaction } & US1 & 0.859 & 0.819 & 0.853 & 0.659 & 0.408 & 0.402 \\
\hline & US2 & 0.776 & & & & & \\
\hline & US3 & 0.804 & & & & & \\
\hline Student-centric learning & SCL1 & 0.722 & 0.751 & 0.750 & 0.601 & 0.251 & 0.498 \\
\hline
\end{tabular}




\begin{tabular}{|c|c|c|c|c|c|c|c|}
\hline & SCL2 & 0.836 & & & & & \\
\hline \multirow[t]{2}{*}{ Less demand on teacher } & LDT2 & 0.712 & 0.71 & 0.712 & 0.553 & 0.458 & 0.452 \\
\hline & LDT3 & 0.774 & & & & & \\
\hline \multirow[t]{3}{*}{$\begin{array}{l}\text { Less demand on physical } \\
\text { facilities }\end{array}$} & LDF1 & 0.761 & 0.765 & 0.764 & 0.520 & 0.461 & 0.521 \\
\hline & LDF2 & 0.720 & & & & & \\
\hline & LDF3 & 0.683 & & & & & \\
\hline \multirow[t]{3}{*}{ Improved reading culture } & $\mathrm{IRC} 2$ & 0.672 & 0.761 & 0.759 & 0.513 & 0.456 & 0.407 \\
\hline & IRC3 & 0.785 & & & & & \\
\hline & IRC4 & 0.700 & & & & & \\
\hline \multirow[t]{2}{*}{ Improved performance } & IP1 & 0.743 & 0.659 & 0.665 & 0.499 & 0.358 & 0.377 \\
\hline & IP2 & 0.667 & & & & & \\
\hline \multirow[t]{3}{*}{ Communication \& interaction } & CMI1 & 0.648 & 0.724 & 0.722 & 0.465 & 0.449 & 0.374 \\
\hline & CMI2 & 0.694 & & & & & \\
\hline & CMI3 & 0.716 & & & & & \\
\hline \multirow[t]{2}{*}{ Collaboration \& resource sharing } & CLR1 & 0.828 & 0.728 & 0.735 & 0.583 & 0.449 & 0.438 \\
\hline & CLR2 & 0.694 & & & & & \\
\hline
\end{tabular}

PROBLEMS

OF EDUCATION

IN THE $21^{\text {st }}$ CENTURY

Vol. 78 , No. 1,2020

37

\section{Reliability}

The reliability or internal consistency of a scale ascertains how measures of the same constructs hang together (Pallant, 2011). Internal consistency is indicated if Cronbach's alpha values are greater than 0.7 . From Table 6 above, it is observed that while some variables indicate acceptable and good reliability, others (effort expectancy, social influence, mobile learning conditions, behavioural intention, system quality and improved performance) have marginally acceptable Cronbach alpha coefficients (Chinomona \& Cheng, 2013).

However, it has been observed that Cronbach's alpha coefficients are sensitive to the number of items in a scale (Gliem \& Gliem, 2003), such that scales having fewer than ten items often result in Cronbach's alpha coefficients as low as 0.5 (Pallant, 2011). While some researchers (such as (Briggs \& Cheek, 1986)) suggested that a scale with mean inter-item correlations (MIC) coefficients in the range of 0.2 to 0.4 is reliable, others (for example (Clark \& Watson, 1995)) recommended a range of 0.15 to 5.0 depending on the nature of construct being measured. Since the number of items used in the various subscales in this study is below ten, the mean inter-items correlation for each construct is also computed and considered. In this case, all constructs are considered reliable.

\section{Validity}

In this research, convergent or construct validity and discriminant validity were used to measure the validity of the scale. Convergent validity ascertains the level of agreement between items that measure the same construct (Guo, Aveyard, Fielding, \& Sutton, 2008). Convergent validity is assessed by observing factor loadings, composite reliability (CR) values, and average variance extracted (Field, 2009; Hair et al., 2009). These measures determine if variables converge at some point. The rule of thumb is that $\mathrm{CR}$ values should be greater than 0.6 , and average variance extracted or estimated (AVE) should be greater than 0.5 (Hair et al., 2009). Additionally, factor loadings should be greater than 0.5 . 
John, G. CHAKA, Irene GOVENDER. Implementation of mobile learning using a social network platform: Facebook

PROBLEMS

OF EDUCATION

IN THE $21^{\text {st }}$ CENTURY

Vol. 78 , No. 1,2020

38

Table 6 shows that all factors have acceptable loadings, just as all constructs have acceptable CR. Similarly, most of the constructs indicate acceptable values for AVE $(>0.5)$, while others (with AVE >0.4) are marginally acceptable (Chinomona \& Cheng, 2013). Service quality (SQ) with $\mathrm{AVE}<0.4$ seems to be the only concern in this case.

\section{Discriminant Validity}

Discriminant validity measures the distinctiveness of constructs in a given model (Guo et al., 2008). In this research, discriminant validity is assessed by ascertaining the maximum shared variance in each construct, which should be less than AVE. As can be clearly seen from Table 6 , all constructs in the study passed the discriminant validity test.

\section{Multicollinearity}

A check to ensure the non-violation of the assumptions of multicollinearity was carried out. Multicollinearity ascertains the extent to which the various constructs are related to or measure the same concept/object. Specifically, the tolerance and variance inflation factor (VIF) values in the coefficient table were inspected against the prescribed values (tolerance value $<$ 0.10 , or a VIF value $>10$ for the presence of multicollinearity) (Pallant, 2011). Results indicate a non-violation of multicollinearity assumption as the lowest tolerance value was 0.647 and the highest VIF value was 1.415 .

\section{Improvement of the Measurement Model and Results}

After exhausting all the possible avenues towards improving the model, the model still did not fit the data well. A further improvement on the model was not possible without dropping some variables. To improve the model in this regard while ensuring the retention of most vital components of the model, it became imperative to drop anxiety from the acceptance measures, and then system quality and students'-centric learning from the success measures. These changes yielded some more improvements on the model. The final measurement model and fit indices are presented in Figure 2 and Table 7 respectively. 
Figure 2

Measurement model for the acceptance and success of m-learning in colleges of education

PROBLEMS

OF EDUCATION

IN THE $21^{\text {st }}$ CENTURY

Vol. 78 , No. 1,2020

39

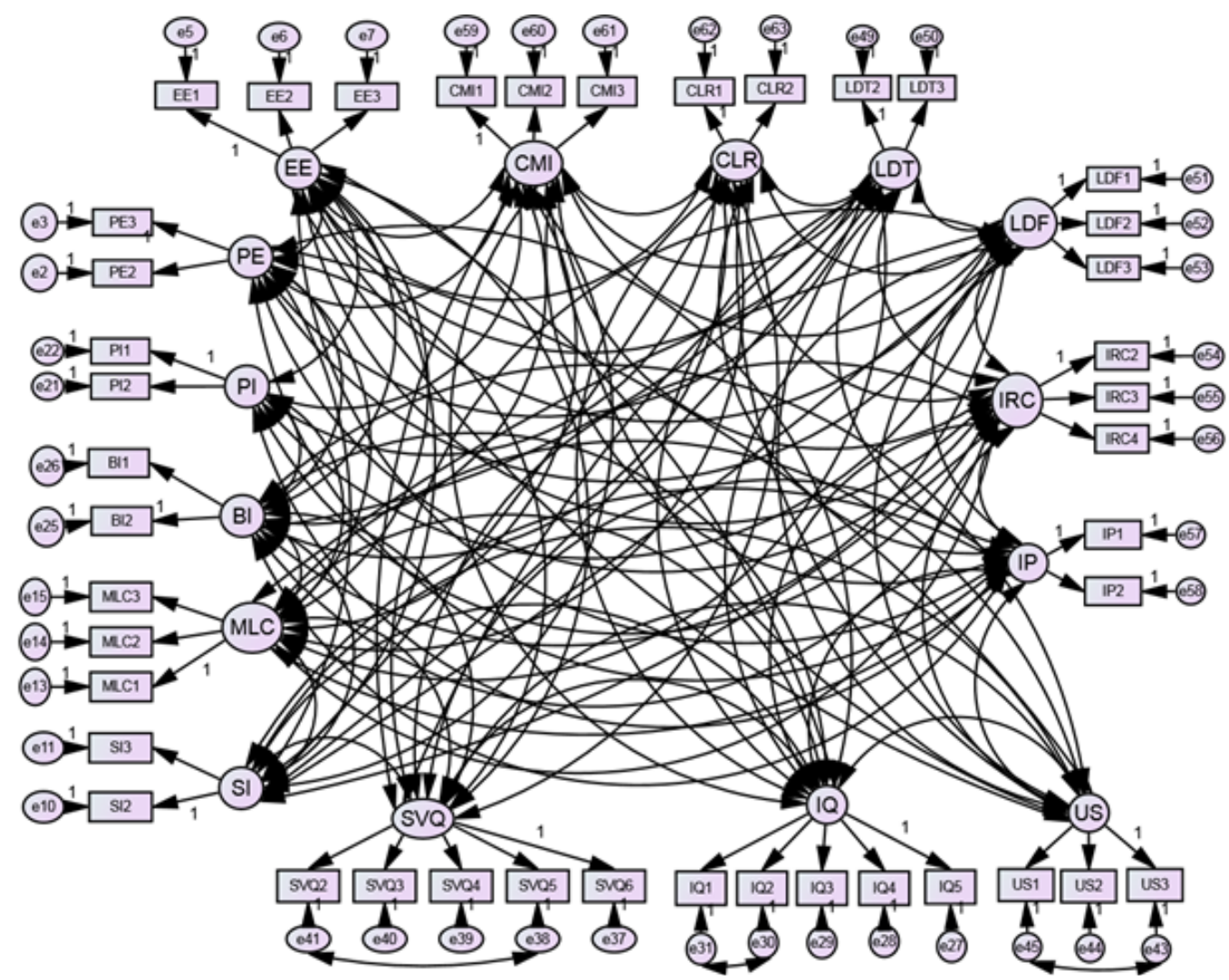

The measurement model shown in figure 2 consists of different components including rectangular boxes, circle/ellipses, error terms, non-causal or non-directional relationships (correlations), causal relationships or directional relationships (single headed arrows). The rectangular boxes represent observed or measured variables. In this case, they represent measured items (questions) that were specified in the measuring instrument. The components represented as circles/ellipses are latent or unobserved variables including exogenous or independent variables (IVs) and endogenous or dependent (DVs). These variables were measured through the variables in rectangular boxes as indicated by the path coefficients (single headed arrows that flow from the IVs/DVs to the measured variables). The circles/ellipses with numbers that are preceded by the letter 'e' are error terms or residuals. They represent omitted causes or errors on each measured variable. The double-headed arrows connecting two error terms represent the residuals' covariance. All unobserved variables are interrelated with each other using double-headed arrows called correlations. 
John, G. CHAKA, Irene GOVENDER. Implementation of mobile learning using a social network platform: Facebook

PROBLEMS

OF EDUCATION

IN THE $21^{\text {st }}$ CENTURY

Vol. 78, No. 1,2020

40 Table 7

Final fit indices of the proposed measurement model

\begin{tabular}{cc}
\hline Fit Index & Observed Value \\
\hline CMIN & 1094.109 \\
\hline df & 718 \\
\hline CMIN/Df & 1.524 \\
\hline GFI & .868 \\
\hline IFI & .920 \\
\hline TLI & .901 \\
\hline CFI & .917 \\
\hline RMSEA & .040 \\
\hline
\end{tabular}

Table 7 indicates that with the exception of CFI which has a marginally acceptable index, all the other indices are within the prescribed thresholds (Hoe, 2008; Tabachnick \& Fidell, 2007)2007. On this basis, the measurement model is considered acceptable.

\section{The Structural Model}

Based on the acceptability of the measurement model, confirmatory factor analysis was applied to the structural model. Composite scores for each construct were calculated by averaging measured variables (questions) identified in the measurement model analysis. These were then used in the model to test with SEM. As can be seen in Figure 2, Mobile Learning Conditions (MLC) had two direct relationships - one relationship with Behavioural Intention (BI), and the second relationship with Actual Use of Mobile Learning (AUML).

An assessment of the structural model showed that the model has adequate or marginally acceptable fit. It was observed from the model that if the relationship between Personal Innovativeness (PI) and BI is removed, the relationships between MLC and BI as well as that between MLC and AUML become significant. Furthermore, if PI is completely removed from the model, the model's fit improves negligibly. The action further lowers the variance in BI explained.

However, since dropping PI from the model did not result in any significant improvement, PI was retained in the model. The structural model is presented in Figure 3. 


\section{Figure 3}

Structural model for the acceptance and success of m-learning

PROBLEMS

OF EDUCATION

IN THE $21^{\text {st }}$ CENTURY

Vol. 78 , No. 1,2020

41

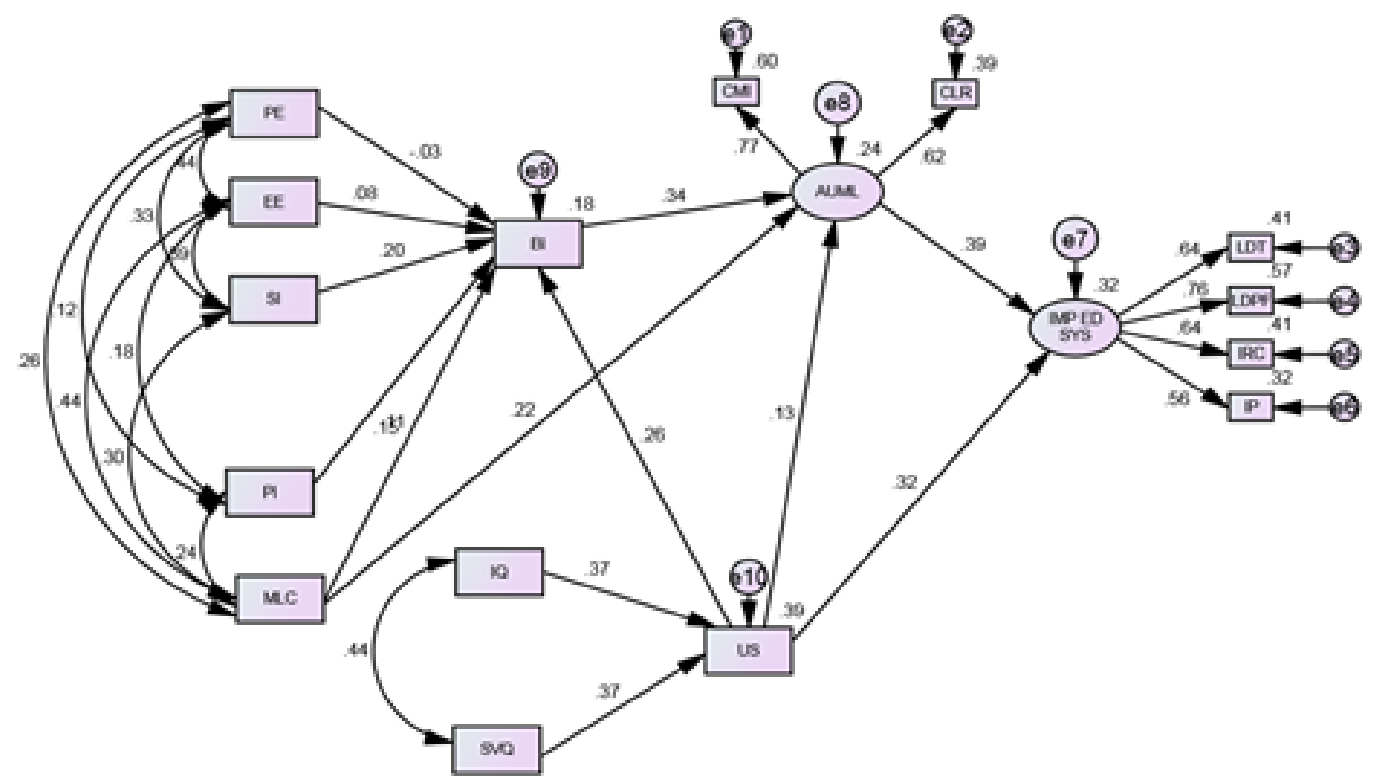

In the structural model, the rectangular boxes represent observable IVs and DVs, while the circles/ellipses represent latent variables. Table 8 presents the overall fit indices of the model.

\section{Table 8}

Overall fit indices for the structural model

\begin{tabular}{cc}
\hline Fit Index & Observed Value \\
\hline CMIN & 205.573 \\
\hline$d f$ & 66 \\
\hline CMIN/df & 3.115 \\
\hline GFI & .922 \\
\hline IFI & .884 \\
\hline TLI & .836 \\
\hline CFI & .881 \\
\hline RMSEA & .081 \\
\hline
\end{tabular}

Table 8 reveals that RMSEA has a mediocre or average fit (MacCallum, Widaman, Preacher, \& Hong, 2001) while IFI, TLI, CFI have marginally acceptable or adequate fit indices. GFI on the one hand has an acceptable index. This suggests that the model is marginally acceptable or adequate.

In addition, although the indices shown in Table 8 may suggest that the model has marginal or mediocre fit, Schunn and Wallach (2005) caution that goodness-of-fit measures for a model should not be regarded as alpha-levels. They maintain (p.117) that "a model should not be thrown out simply because it does not exceed some arbitrarily defined threshold for 
John, G. CHAKA, Irene GOVENDER. Implementation of mobile learning using a social network platform: Facebook

PROBLEMS

OF EDUCATION

IN THE $21^{\text {st }}$ CENTURY Vol. 78 , No. 1,2020

goodness-of-fit". Rather, goodness-of-fit should be compared to previous ones in the domain. In other words, a relatively weak fit to the data can be acceptable in terms of newer models. Based on this argument, this structural model is considered acceptable since it is a new formulation, even though derived from three already validated theories. Further research should be carried out to improve the model.

The model indicates that behavioural intention (BI) is the main variable that is used to measure the acceptance of mobile learning. BI depends on five independent variables (PE, EE, SI, PI, and MLC). BI relates directly with two success measures - AUML and US, while MLC also relates directly to AUML. These relationships represent the operational interplay between the acceptance of mobile learning and its success. AUML is a latent variable, which is observed or manifests itself through two variables - Communication and Interaction (CMI), and Collaboration and Resource Sharing (CLR). The overall dependent variable that represents the net benefit of the study is Improved Educational System (IMP-ED_SYS). This variable is also a latent variable, which is observed or manifests itself through four other variables (LDT, LDF, IRC, and IP). The endogenous variable User Satisfaction (US) depends on two independent variables - Information Quality (IQ) and Service Quality (SVQ). US plays a mediating role between these two variables and the other three endogenous variables (BI, AUML, and IMP ED_SYS). Table 9 presents the regression estimates from the model.

\section{Table 9}

Regression weights of the structural model

\begin{tabular}{|c|c|c|c|c|c|c|c|}
\hline & & & Estimate & S.E. & C.R. & $\mathbf{P}$ & Label \\
\hline US & $<--$ & IQ & .251 & .033 & 7.653 & $* * *$ & par_9 \\
\hline US & $<--$ & SVQ & .250 & .033 & 7.563 & $* * *$ & par_10 \\
\hline $\mathrm{BI}$ & $<--$ & $\mathrm{EE}$ & .060 & .046 & 1.293 & .196 & par_5 \\
\hline $\mathrm{BI}$ & $<--$ & SI & .167 & .049 & 3.436 & $* * *$ & par_6 \\
\hline $\mathrm{BI}$ & $<--$ & $\mathrm{PI}$ & .163 & .058 & 2.792 & .005 & par_7 \\
\hline $\mathrm{BI}$ & $<--$ & MLC & .081 & .042 & 1.917 & .055 & par_23 \\
\hline $\mathrm{BI}$ & $<--$ & US & .174 & .034 & 5.074 & $* * *$ & par_24 \\
\hline $\mathrm{BI}$ & $<--$ & PE & -.026 & .054 & -.481 & .631 & par_26 \\
\hline AUML & $<--$ & $\mathrm{BI}$ & .360 & .071 & 5.064 & $* * *$ & par_8 \\
\hline AUML & $<--$ & MLC & .166 & .049 & 3.395 & $* * *$ & par_12 \\
\hline AUML & $<--$ & US & .096 & .046 & 2.085 & .037 & par_27 \\
\hline IMP_ED_SYS & $<--$ & AUML & .251 & .055 & 4.599 & $* * *$ & par_11 \\
\hline IMP_ED_SYS & $<--$ & US & .148 & .029 & 5.017 & $* * *$ & par_25 \\
\hline $\mathrm{CMI}$ & $<--$ & AUML & 1.000 & & & & \\
\hline CLR & $<--$ & AUML & .564 & .083 & 6.793 & $* * *$ & par_1 \\
\hline LDT & $<--$ & IMP_ED_SYS & 1.000 & & & & \\
\hline LDF & $<--$ & IMP_ED_SYS & 1.461 & .154 & 9.497 & $* * *$ & par_2 \\
\hline IRC & $<--$ & IMP_ED_SYS & 1.133 & .129 & 8.750 & $* * *$ & par_3 \\
\hline IP & $<--$ & IMP_ED_SYS & .828 & .104 & 7.955 & *** & par_4 \\
\hline
\end{tabular}

Figure 2 and Table 9 are used to address the various research questions as highlighted below. 


\section{Discussion}

Joint influence of acceptance factors and user satisfaction on behavioural intention

As can be seen from Table 9, MLC does not have a significant influence on behavioural intention to accept m-learning. The only acceptance measures or independent variables that significantly predict $\mathrm{BI}$ are SI $(\mathrm{ESC}=.167, p<.005)$ and $\mathrm{PI}(\mathrm{ESC}=.163, p=.005)$. As already stated, the influence of MLC on BI becomes significant if the effect of PI is suppressed. The two independent variables have positive effects on the intention of stakeholders to accept mobile learning. This means that an increase in one standard deviation of SI will result in an increase of $16.7 \%$ in the value of the standard deviation of BI. Similarly, an increase of one standard deviation of PI will result in an increase of $16.3 \%$ in the value of the standard deviation of BI.

Furthermore, the research revealed that US has a significant influence on BI $(\mathrm{ESC}=$ $.174, p<.005)$. This means that an increase in the value of the standard deviation of US will cause an increase of $17.4 \%$ in the value of standard deviation of BI. US has a stronger effect on BI as compared to the individual effects of SI and PI. This is an indication that the user satisfaction is a driving force in the intention of stakeholders to accept mobile learning. The three predictors account for $18 \%$ of the variance in the intention of stakeholders in Colleges of Education in Nigeria to accept mobile learning using Facebook.

\section{Influences of Mobile Learning Conditions, Behavioural Intention and User Satisfaction on Actual Use of Mobile Learning}

Mobile learning conditions (MLC) significantly predict the actual use of mobile learning (AUML). This effect is positive ( $\mathrm{ESC}=.166, p<.005$ ). The implication of this result is that an increase in one standard deviation MLC will result in an increase of $16.6 \%$ in the value of the standard deviation of AUML. This result agrees with the results of Venkaesh et al. (2003) as well as Venkatesh et al. (2012). The results suggest that the actual use of mobile learning by stakeholders in Colleges of Education will depend on the mobile learning conditions.

Table 9 further shows that $\mathrm{BI}(\mathrm{ESC}=.360, p<.005)$ significantly predicts AUML as did $\mathrm{US}(\mathrm{ESC}=.096, p=.037)$. The effects of the two variables are positive, meaning that an increase in one standard deviation of BI will yield an increase in the actual use of mobile learning by $36.6 \%$ of the value of its standard deviation. Similarly, an increase in one standard deviation of US will result in an increase of $9.6 \%$ in the value of the standard deviation of AUML by stakeholders.

The implication is that BI has the greatest effect on the actual use of mobile learning. Thus, the more stakeholders develop an intention to use mobile learning, the more they use it. The two variables explain $24 \%$ of the variance in the actual use of mobile learning.

The conceptual model shows that user satisfaction is an endogenous or dependable variable, which has relationships with several factors including the actual use of mobile learning (AUML), information quality (IQ) and service quality (SVQ). To assess the influence of AUML on US, the relationship between the two variables was reversed. The results indicate that AUML does not significantly predict US. This is contrary to the finding of Delone and McLean (2003). In other words, the research indicates that the actual use of mobile learning was not a significant determinant of the satisfaction of stakeholders in Colleges of Education.

Rather, two exogenous (independent) variables - Information Quality $(\mathrm{ESC}=.251$, $p<.005)$ and Service Quality (ESC $=.250, p<.005)$ significantly predict the satisfaction of stakeholders in mobile learning. The two variables explained $39 \%$ of the variance in the satisfaction of stakeholders. 
John, G. CHAKA, Irene GOVENDER. Implementation of mobile learning using a social network platform: Facebook

PROBLEMS

OF EDUCATION

IN THE $21^{\text {st }}$ CENTURY

Vol. 78, No. 1,2020
Influences of Actual Use of Mobile Learning and User
Satisfaction in an Improved Educational System

The study reveals that AUML (ECS $=.251, p<.005$ ) has a significant influence on IMPED_SYS, as did US (ESC $=.148, p<.005)$. The influences of the two variables are positive. This means that an increase in one standard deviation of AUML results in an increase of $25.1 \%$ in the value of the standard deviation of IMP_ED_SYS. Similarly, an improvement of one standard deviation of US yields an improvement of $14.1 \%$ in the value of the standard deviation of IMP_ED_SYS. This shows that AUML has the strongest influence on IMP_ED_SYS. The two variables explain $32 \%$ of the variance in IMP_ED_SYS. This result may be suggesting that other factors exist that account for the remaining variance in IMP_ED_SYS.

\section{Feedback from the Improved Educational System on Actual Use of Mobile Learning and User Satisfaction}

The feedback that results from the net benefits of mobile learning (IMP_ED_SYS) leading to satisfaction and actual use of mobile learning could not be ascertained with the quantitative data. However, it is expected that stakeholders in Colleges of Education will become satisfied due to the level of improvement that mobile learning brings to the current practices of teaching and learning in the institutions. In addition, improvement in the teaching and learning conditions in the colleges should result in the continuous use of mobile learning. Prior studies have not been able to convincingly show the need for a social network site as a learning and teaching medium. This study has provided a deeper insight into the use of Facebook as a medium for teaching and learning among students in teacher education. The implication of these findings is that more students can gain access to education if implemented properly. More importantly, it is envisaged that this experience of using Facebook as a teaching and learning medium, can influence their teaching approach in schools.

\section{Conclusions}

The research revealed that the use of mobile learning using a social networking application such as Facebook may have strong support in Colleges of Education in Nigeria in view of the derived benefits. Furthermore, the results indicate that the intention of stakeholders depend significantly on the influence of important others, personal innovativeness and level of satisfaction of users with the technology. In addition, the actual use of mobile learning largely depends on the mobile learning conditions, behavioural intention and user satisfaction. These in turn result in an improved educational system. This improved educational system is reflected in less demand for facilities such as classrooms and books, improved reading culture, and improved performance of students. The contribution of this research has been to confirm that use of Facebook is an important path to improve not only learning, but improved access to education in a context of teacher education that is often relegated to the background. It is therefore necessary to harness the power of mobile learning to increase access and possibly improve learning.

\section{References}

Abu-Al-Aish, A., \& Love, S. (2013). Factors influencing students' acceptance of m-learning: An investigation in higher education. The International Review of Research in Open and Distance Learning, 14(5), 82-107. https://doi.org/10.19173/irrodl.v14i5.1631 
Adedoja, G., Adelore, O., Egbokhare, F., \& Oluleye, A. (2013). Learners' acceptance of the use of mobile Pphones to deliver tutorials in a distance learning context: A case study at the University of Ibadan. The African Journal of Information Systems, 5(3), 80-93. https://www.semanticscholar.org/paper/ Learners\%E2\%80\%99-Acceptance-of-the-Use-of-Mobile-Phones-to-Adedoja-Adelore/0ff02ad9 dea7c71ed73d1200eec1296b5cfaeaf2

Adewole, E. G., \& Fakorede, S. O. (2013). Strengthening the Nigerian higher education system through the use of information communication technology. International Journal of Social Science and Education, 3(4), 1006-1012. http://ijsse.com/sites/default/files/issues/2013/v3i4/papers/Paper-15. pdf

Ahmed, A. K. (2013). Teacher-centered versus learner-centered teaching style. The Journal of Global Business Management, 9(1), 22-34. http://www.jgbm.org/page/3\%20Ahmed\%20Khaled\%20 Ahmed.pdf

Ahn, J. (2011). The effect of social network sites on adolescents' social and academic development: Current theories and controversies. Journal of the American Society for Information Science and Technology, 62(8), 1435-1445. https://doi.org/10.1002/asi.21540

Alharbi, S., \& Drew, S. (2014). Mobile learning-system usage: Scale development and empirical tests. International Journal of Advanced Research in Artificial Intelligence, 3(11), 31-47.

Alsereihy, H. A, \& Al Youbi, A. A. (2014). Towards applying social networking in higher education: Case study of Saudi Universities. MAGNT Research Report, 2(4), 217-231. https://www. semanticscholar.org/paper/Towards-Applying-Social-Networking-in-Higher-Case-AlsurehiYoubi/ff71ff4928dc8b0aab7a696ac3aa10e7126d3f50

Asiyai, R I. (2013). Challenges of quality in higher education in Nigeria in the 21st century. International Journal of Educational Planning \& Administration, 3(2), 159-172. https://www.ripublication. com/ijepa/ijepav3n2_07.pdf

Barrett, P. (2007). Structural equation modelling: Adjudging model fit. Personality and Individual Differences 42, 815-824.

Bishara, S. (2015). Active and traditional teaching of mathematics in special education. Creative Education, 6, 2313-2324. http://dx.doi.org/10.4236/ce.2015.622238

Briggs, S. R., \& Cheek, J. M. (1986). The role of factor analysis in the development and evaluation of personality scales. Journal of Personality, 54, 106-148.

Buzzetto-More, N. A. (2012). Social networking in undergraduate education. Interdisciplinary Journal of Information, Knowledge, and Management, 7, 63-90. http://www.ijikm.org/Volume7/ IJIKMv7p063-090Buzzetto611.pdf

Chaka, J.G. (2018). Towards improving teaching and learning in colleges of education using mobile learning - The Nigerian perspective. Unpublished thesis - University of KwaZulu-Natal., South Africa.

Chaka, J. G., \& Govender, I. (2017a). Students' perceptions and readiness towards mobile learning in colleges of education: A Nigerian perspective. South African Journal of Education, 37(1), 1-12. https://doi.org/10.15700/saje.v37n1a1282

Chaka, J. G., \& Govender, I. (2017b). Staff acceptance of mobile learning: The case of Nigerian colleges of education. Journal of New Generation Sciences (JNGS), 15(1), 223-242. https://hdl.handle. net/10520/EJC-c85efa1fd

Chinomona, R., \& Cheng, J. M. (2013). Distribution channel relational cohesion exchange model: A small-to-medium enterprise manufacturers' perspective. Journal of Small Business Management, $51(2), 256-275$.

Clark, L. A., \& Watson, D. (1995). Constructing validity: Basic issues in objective scale development Psychological Assessment, 7(3), 309-319.

Clark, N., \& Ausukuya, C. (2013). An overview of education in Nigeria. World Education News and Reviews website: http://wenr.wes.org/2013/07/an-overview-of-education-in-nigeria

Creswell, J. W. (2014). Research design: Qualitative, quantitative and mixed methods approaches (3rd ed.). SAGE Publications.

Delone, W. H., \& McLean, E. R. (2003). The DeLone and McLean model of information systems success: A ten-year update. Journal of Management Information Systems, 19(4), 9-30.

Dunn, L. A. (2013). Teaching in higher education: Can social media enhance the learning experience? Interdisciplinary Science Education, Technologies and Learning-The University of Glasgow, 1-1. 
John, G. CHAKA, Irene GOVENDER. Implementation of mobile learning using a social network platform: Facebook

PROBLEMS

OF EDUCATION

IN THE $21^{\text {st }}$ CENTURY Vol. 78 , No. 1,2020

46

Field, A. (2009). Discovering statistics using SPSS. SAGE Publications.

Gliem, J. A., \& Gliem, R. R. (2003). Calculating, interpreting, and reporting Cronbach's Alpha reliability coefficient for likert-type scales. Paper presented at the Midwest Research-to-Practice Conference in Adult, Continuing, and Community Education, Columbus, Ohio. https://scholarworks.iupui. edu/handle/1805/344

Gorghiu, G., Iordache, D. D., Pribeanu, C., \& Lamanauskas, V. (2018). Educational potential of online social networks: Gender and cross-country analysis. Problems of Education in the 21st Century, 76 (5), 620-632.

Gülbahar, Y. (2014). Current state of usage of social media for education: Case of Turkey. Journal of Social Media Studies, 1(1), 53-59.

Guo, B., Aveyard, P., Fielding, A., \& Sutton, S. (2008). Testing the convergent and discriminant validity of the decisional balance scale of the transtheoretical model sing the multi-trait multi-method approach. Psychology of Addictive Behaviour, 22(2), 288-294.

Hair, J. F., Black, W. C., Babin, B. J., \& Anderson, R. E. (2009). Multivariate data analysis (7th Ed.). Prentice Hall.

Hoe, S. L. (2008). Issues and procedures in adopting structural equation modeling technique. Journal of Applied Quantitative Methods, 3(1), 76-83.

Hooper, D., Coughlan, J., \& Mullen, M. (2008). Structural equation modelling: Guidelines for determining model-fit. Electronic Journal of Business Research Methods, 6(1), 53-60.

Ilogho, J. E. (2015). The role of picture books in promoting reading culture among Nigerian children: Implication for libraries and development of leadership qualities. International Journal of Academic Library and Information Science and Technology, 3(2), 65-71.

Jaja, J. M. (2013). Higher education in Nigeria: Its gain, its burden. Global Journal of Human and Social Science Linguistics and Education 13, (14), 20-29.

Karpinski, A. C, \& Duberstein, A. (2009). A description of Facebook use and academic performance among undergraduate and graduate students. Research News. http://researchnews.osu.edu/ archive/facebookusers.htm

Klopfer, E., Osterweil, S., Groff, J., \& Haas, J. (2009). Using technology of today in the classroom of today. The education arcade website: http://creativecommons.org/licenses/by/3.0

Kumar, R. (2011). Research methodology - A step-by-step for beginners (3rd Ed.). SAGE Publications.

Lin, H.-H., Wang, Y.-S., \& Li, C.-R. (2016). Assessing mobile learning systems success. International Journal of Information and Education Technology, 6(7), 576-579. https://doi.org/10.7763/ IJIET.2016.V6.754

MacCallum, R. C., Widaman, K. F., Preacher, K., \& Hong, S. (2001). Sample size in factor analysis: The role of model error. Multivariate Behavioral Research, 36, 611-637.

Mazman, S. G., \& Usluel, Y. K. (2010). The usage of social networks in educational context. World Academy of Science, Engineering and Technology, 3(1), 338-342.

Ogunyinka, E. K., Okeke, T. I., \& Adedoyi, R. C. (2015). Teacher education and development in Nigeria: An analysis of reforms, challenges and prospects. Education Journal, 4(3), 111-122.

Okojie, J. (2013). Quality assurance and the challenges of mandate delivery in Nigerian Universities. Paper presented at the 18th Convocation Lecture, Lagos State University, Lagos Nigeria.

Osang, F. B., \& Ngole, J. (2014). Mobile learning implementation: Readiness of the National Open University of Nigeria. International Journal of Emerging Technology and Advanced Engineering, $4(11), 25-32$.

Otoo, E. (2015). Effects of Boko Haram on Nigeria's children. http://www.globalfundforchildren.org/ effects-of-boko-haram-on-nigerias-children/

Pallant, J. (2011). SPSS survival manual: A step by step guide to data analysis using SPSS (4th Ed.). Allen \& Unwin.

Pasek, J., More, E., \& Hargittai, E. (2009). Facebook and academic performance: Reconciling a media sensation with data. First Monday, 14(5). http://firstmonday.org/article/view/2498/2181

Schreiber, J. B., Nora, A., Stage, F. K., Barlow, E. A., \& King, J. (2006). Reporting structural equation modelling and confirmatory factor analysis results: A review. The Journal of Educational Research, 99(6), 323-337.

Schunn, C. D., \& Wallach, D. (2005). Evaluating goodness-of-fit in comparison of models to data Psychologie der Kognition: Reden and Vorträge anlässlich der Emeritierung von Werner Tack (pp. 115-135). University of Saarland Press. 
Selwyn, N. (2012). Social media in higher education. http://www.educationarena.com/pdf/sample/ sample-essay-selwyn.pdf

Serbessa, D. D. (2006). Tension between traditional and modern teaching-learning approaches in Ethiopian primary schools. Journal of International Cooperation in Education, 9(1), 123-140.

Shonola, A. S., \& Mike, S. J. (2014). Mobile learning security concerns from university students' perspectives. In: Proceedings of 2014 International Conference on Interactive Mobile Communications Technologies and Learning. Thessaloniki, Greece. Nove 13-14.

Shembilu, A. (2013). Importance of social networking for student participation in education in Tanzania. Blekinge Institute of Technology, Karlskrona, Sweden.

Tabachnick, B. G., \& Fidell, L. S. (2007). Using multivariate statistics (5th Ed.). Pearson Education.

Tella, A. (2011). Availability and use of ICT in south-western Nigeria colleges of education. International Multidisciplinary Journal, Ethiopia, 5(5), 315-331.

Thomas, T. D., Singh, L., \& Gaffar, K. (2013). The utility of the UTAUT model in explaining mobile learning adoption in higher education in Guyana. International Journal of Education and Development using Information and Communication Technology, 9(3), 71-85.

Traxler, J. (2007). Defining, discussing, and evaluating mobile learning: The moving finger writes and having writ.... International Review of Research in Open and Distance Learning, 8(2), 1-12. https://doi.org/10.19173/irrodl.v8i2.346

Venkatesh, V., Morris, M. G., Davis, G. B., \& Davis, F. D. (2003). User acceptance of information technology: Toward a unified view. MIS Quarterly, 27(3), 425-478.

Venkatesh, V., Thong, J. Y., \& Xu, X. (2012). Consumer acceptance and use of information technology: Extending the unified theory and use of technology. MIS Quarterly, 36(1), 157-178.

Walker, R., Voce, J., Nicholls, J., Swift, E., Ahmed, J., \& Horrigan, S. (2014). 2014 survey of technology enhanced learning for higher education in the UK. Universities and Colleges Information Systems Association.

Yapici, I. U., \& Havedanli, M. (2014). Educational use of social networks: Facebook case study. European Journal of Research on Education, 16-21.

Received: September 25, 2019

Accepted: January 05, 2020

Cite as: Chaka, J. G., \& Govender, I. (2020). Implementation of mobile learning using a social network platform: Facebook. Problems of Education in the $21^{\text {st }}$ Century, 78(1), 24-47. https://doi.org/10.33225/pec/20.78.24

\begin{tabular}{|ll|}
\hline John Chaka & PhD, Lecturer, Department Computer Science, Federal College of Education, \\
& Pankshin, Plateau State, Nigeria. \\
& E-mail: chakajohn@yahoo.com \\
& ORCID: http://orcid.org/0000-0003-1483-4959 \\
& \\
\hline $\begin{array}{l}\text { Irene Govender } \\
\text { (Corresponding author) }\end{array}$ & PhD, Professor, University of KwaZulu-Natal, Westville, South Africa. \\
& ORCID: http://orid.org/0000-0002-4499-1091 \\
\hline
\end{tabular}

